\title{
The relationship between 25-hydroxyvitamin D concentration and liver enzymes in healthy adults: A Cross-sectional Study
}

\section{Ji-nian Wang}

Anhui Medical University

Li Li

Zhejiang University

Hua-qing Hu

Anhui Medical University

Qi Yan

Anhui Medical University

Ying Liu

Anhui Medical University

Shu-qi Cheng

Anhui Medical University

Pan-pan Lian

Anhui Medical University

Faming Pan

Anhui Medical University

Tao Xu ( $\nabla$ xutao@ahmu.edu.cn )

Anhui Medical University

\section{Research}

Keywords: Vitamin D, Liver function, GGT, ALT, ALP

Posted Date: June 12th, 2020

DOI: https://doi.org/10.21203/rs.3.rs-34661/v1

License: (c) (1) This work is licensed under a Creative Commons Attribution 4.0 International License.

Read Full License 


\section{Abstract}

Background Studies have shown that serum 25-hydroxyvitamin D $(25(\mathrm{OH}) \mathrm{D})$, a product of exogenous vitamin $\mathrm{D}$, plays an influential role in calcium and phosphorus balance, anti-inflammation, and cardiovascular protection. There were long-standing interests in the potential benefits of vitamin $D$ for preventing liver diseases. Investigations showed that 25(OH)D was increased in adolescents with abnormal liver function. Yet data about the relationship of 25(OH)D concentration and liver enzymes from prospective cross-sectional study was limited. The present study is undertaken to examine whether serum 25-hydroxyvitamin D and glutamyl transferase (GGT), alanine aminotransferase (ALT) and alkaline phosphatase (ALP) were closely related. Methods The cross-sectional study of 368 healthy volunteers with no history of liver diseases was used to examine risk factors. Pearson correlation (or Spearman correlation for skewed variables) was performed to assess associations between GGT, ALT, and ALP and 25(OH)D. Linear regression analysis was conducted with GGT, ALT, and ALP as dependent variables in separate models. Results The results found no significant difference between ALT and ALP in different vitamin D groups $(25(\mathrm{OH}) \mathrm{D}<25 \mathrm{nmol} / \mathrm{L} \otimes 25-50 \mathrm{nmol} / \mathrm{L}$ and $>50 \mathrm{nmol} / \mathrm{L}$ ) (Kruskal-Wallis test, all $p>$ 0.05). In multiple linear regression analysis, GGT, ALT and ALP levels remained unrelated to $25(\mathrm{OH}) \mathrm{D}$ concentration after adjusting covariates including age, BMl, sex, BuN, Cr, UA, AST, Ghb, ALB, WBC, cholesterol, HDL, LDL, cholesterol, and total protein. (All $p>0.1$ ). Conclusion This study suggested that there was no association between the $25(\mathrm{OH}) \mathrm{D}$ concentration and the levels of GGT, ALT or ALP in normal population.

\section{Background}

Vitamin D originates from skin synthesis as a result of exposure to sunlight in vivo, supplementary and dietary vitamin D intake in vivo[1]. It is a group of liposoluble steroid derivatives, responsible for maintaining the strength of bones. In addition, vitamin $D$ is able to reduce the risk of heart diseases, diabetes, breast cancer[2]. As we all know, suboptimal 25-hydroxyvitamin D3 is produced by exogenous vitamin $D$ through liver hydroxylation, which can be used as a biomarker of vitamin $D$ levels owing to its long-term stable levels[3]. Farnik and colleagues have shown that vitamin D not only maintains the balance of calcium and phosphorus, but also regulates immune system, anti-inflammation, anti-fibrosis, and cardiovascular protection function[4]. Recently, scientists confirmed that serum 25(OH)D levels were beneficial to clinical prevention of chronic hepatitis $\mathrm{B}[4]$. Low serum $25(\mathrm{OH}) \mathrm{D}$ levels may lead to chronic hepatitis $B$ infection. With deep exploration about new activity of vitamin $D$, it draws more attention from scientists[5].

The correlation between vitamin D deficiency and non-alcoholic fatty liver disease (NAFLD) was reported by Jeon et al. The results demonstrated that liver enzymes can be used as biomarkers for NAFLD of metabolic syndrome[6]. Eliades et al. found decreased serum 25(OH)D concentration in NAFLD patients by meta-analysis of 17 studies, suggesting that vitamin $D$ may play a role in the development of NAFLD[6]. One study showed that vitamin D could exert positive effects on NAFLD and NAFLD-related parameters, if well administered for medium-long periods[7]. However, current evidence on the 
association of 25(OH)D concentration and liver enzymes was insufficient and inconsistent. Naderpoor et al. observed that vitamin D supplementation affected liver enzymes in 54 persons for 16 weeks. Consequently, 25(OH)D concentration was unlinked to liver enzymes in adults with no history of liver diseases, and vitamin D supplementation didn't impact the liver enzymes serum levels in vitamin Ddeficient and overweight people[8]. However, Bahreynian et al. found that higher rates of vitamin D deficiency were observed among individuals with high levels of liver enzymes. Recent study has showed that NAFLD patients have decreased serum $25(\mathrm{OH}) \mathrm{D}$ concentration, and vitamin D may play a role in the development of NAFLD[9]. In order to verify this association between 25(OH)D and liver enemies, exhaustive investigations were undertaken to examine their relationship in healthy people.

\section{Materials And Methods}

\section{Study design and participants}

The study population consisted of 368 healthy volunteers (males and females) with no history of liver diseases who came from the province of Anhui, China. Inclusion criteria were as follows: aged 26-86 years, stable weight for at least 12 months (no weight change $>5 \mathrm{~kg}$ ) and no intention to lose weight or change diet or physical activity for the trial duration, and no known comorbidities. Participants were required to no-vitamin $\mathrm{D}$ intake for at least three months prior to taking part in the study. This study was conducted in accordance with the ethical guidelines of the 1975 Declaration of Helsinki, and informed consent was obtained from all participants. Ethical approval for the present study was obtained from the ethical committee of Anhui Medical University (Protocol ID: 20170248).

Anthropometric measurements

All participants $(n=368)$ underwent physical examinations, including measurements of body weight, height and blood pressure. Body mass index (BMI) was calculated by weight $(\mathrm{kg}) /$ height square $(\mathrm{m} 2)$. Physical health was assessed by a full-body dual-energy X-ray absorptiometer (DEXA) (Madison Lunar Radiation Company, Wisconsin, USA).

\section{Metabolic Measurements}

After resting for at least five minutes, average systolic and diastolic blood pressures were measured from three measurements using an automatic sphygmomanometer(M6 Automatic BP monitor, Omron, Japan).

Fasting venous blood samples were analyzed for $25(\mathrm{OH})$ D concentration (direct competitive chemiluminescent immunoassays, DiaSorin Inc., MN, USA), inter- and intra-analysis coefficient of variation ( $<10 \%$ and $<4 \%$ ). The test included glucose (glucose oxidase assay, YSI 2300 Stat, YSI Inc., OH, USA), insulin, kidney and liver tests, lipid assay (all using commercial enzymatic immunoassays, Beckman Coulter, Australia) and whole blood cell count (Beckman Coulter LH750). 
Insulin sensitivity was measured with hyperinsulinemia-normal glucose clamp as our protocol, including initial intravenous insulin pills $(9 \mathrm{mU} / \mathrm{kg})$, followed by continuous infusion of insulin at a rate of $40 \mathrm{mU} / \mathrm{m} 2 / \mathrm{min}$ for at least 120 minutes. At the same time, adjust the glucose infusion to maintain blood sugar at about 5 millimole/liter. According to the last 30 minutes of clamp and the stable glucose infusion rate, the total insulin stimulated glucose treatment rate ( $M$ value) was calculated.

\section{Statistical analysis}

SPSS version 17 statistical package was used to perform the analyses. The baseline characteristics of the participants were presented as the mean \pm standard deviation (SD) of the normal distribution variable and the median [interquartile range (IQR)] of the non-normal distribution variable. For all the above, a twotailed $p$-value $<0.05$ was considered statistically significant.

\section{Results}

The study population $(n=368)$ included males and females aged $26-86$ years. There were no significant differences in age, fasting FBG, AST, Ghb, cholesterol, HDL, LDL, triglycerides, total protein, ALB, WBC, ALP and 25(OH)D (all $p>0.05$ ). Male participants had a lower BMI $(p=0.01)$, higher diastolic blood pressure $(p=0.03)$, higher urea nitrogen (BuN) $(p<0.001), \operatorname{Cr}(p=0.02)$, uric acid (UA) $(p=0.01), G G T(p=$ $0.01)$ and $\operatorname{ALT}(p=0.03)$. Baseline characteristics of participants are summarized in Table 1. 
Table 1

Baseline characteristic of participants in the cross-sectional study.

\begin{tabular}{|c|c|c|c|c|}
\hline Variable & All participants & Males & Female & p-value \\
\hline${ }^{\mathrm{a}}$ Age (year) & $49.00[12.00]$ & $48.00[11.75]$ & $49.00[12.00]$ & 0.76 \\
\hline $\mathrm{BMI}\left(\mathrm{kg} / \mathrm{m}^{2}\right)$ & $24.61 \pm 3.16$ & $24.61 \pm 3.16$ & $25.27 \pm 3.38$ & 0.01 \\
\hline asBP (mmHg) & $119.0[14.0]$ & $123.0[16.0]$ & $118.0[13.0]$ & 0.12 \\
\hline${ }^{\mathrm{a}} \mathrm{DBP}(\mathrm{mmHg})$ & $75.00[11.00]$ & $79.00[12.00]$ & $73.00[10.00]$ & 0.03 \\
\hline${ }^{\mathrm{a}} \mathrm{GLU}(\mathrm{mmol} / \mathrm{L})$ & $5.28[0.84]$ & $5.36[0.88]$ & $5.15[0.66]$ & 0.59 \\
\hline aBUN (mmol/L) & $5.37[1.75]$ & 5.59 [1.50] & $4.85[1.60]$ & $<0.001$ \\
\hline${ }^{\mathrm{a} C r e a t i n i n e ~(u m o l / L)}$ & $70.00[21.00]$ & $76.00[13.00]$ & $53.00[16.00]$ & 0.02 \\
\hline UA (umol/L) & $332.4 \pm 86.9$ & $366.5 \pm 77.8$ & $265.2 \pm 61.0$ & 0.01 \\
\hline aAST (U/L) & $21.00[9.00]$ & $21.00[9.00]$ & $19.50[7.75]$ & 0.06 \\
\hline a $\mathrm{HbA1C}(\%)$ & $5.50[0.55]$ & $5.50[0.55]$ & $5.50[0.50]$ & 0.29 \\
\hline HDL (mmol/L) & $1.27[0.45]$ & $1.21[0.35]$ & $1.32[0.52]$ & 0.06 \\
\hline${ }^{\mathrm{a}} \mathrm{LDL}(\mathrm{mmol} / \mathrm{L})$ & $2.93[1.05]$ & 3.09 [1.28] & $2.84[1.06]$ & 0.15 \\
\hline aTriglyceride (mmol/L) & $1.38[1.10]$ & $1.93[1.36]$ & $1.11[1.03]$ & 0.06 \\
\hline $\mathrm{TP}(\mathrm{g} / \mathrm{L})$ & $74.70 \pm 3.80$ & $74.49 \pm 3.69$ & $75.12 \pm 3.99$ & 0.71 \\
\hline Alb (g/L) & $47.86 \pm 2.67$ & $44.52 \pm 3.94$ & $49.18 \pm 2.15$ & 0.55 \\
\hline aWBC $\left(10^{9} / \mathrm{L}\right)$ & $5.92[1.90]$ & $5.99[1.26]$ & $5.63[1.47]$ & 0.39 \\
\hline${ }^{\mathrm{a}} \mathrm{GGT}(\mathrm{U} / \mathrm{L})$ & $24.00[27.75]$ & 25.50 [16.75] & $15.5[12.75]$ & 0.01 \\
\hline${ }^{\mathrm{a}} \mathrm{ALT}(\mathrm{U} / \mathrm{L})$ & 21.00 [18.75] & $25.00[20.75]$ & $15.00[12.75]$ & 0.03 \\
\hline${ }^{\mathrm{a}} \mathrm{ALP}(\mathrm{U} / \mathrm{L})$ & $74.00[25.00]$ & $75.00[24.00]$ & $67.00[24.00]$ & 0.06 \\
\hline${ }^{\mathrm{a}} 25(\mathrm{OH}) \mathrm{D}(\mathrm{nmol} / \mathrm{L})$ & 22.85 [18.25] & 22.65 [19.35] & 23.95 [15.65] & 0.83 \\
\hline \multicolumn{5}{|c|}{$\begin{array}{l}\text { ALT: alanine aminotransferase; ALP: alkaline phosphatase; BMI: body mass index; SBP: systolic } \\
\text { blood pressure; DBP: diastolic blood pressure; GGT: } \gamma \text {-glutamyl transferase; HDL: high-density } \\
\text { lipoprotein; LDL: low-density lipoprotein; } 25(\mathrm{OH}) \mathrm{D} \text { : 25-hydroxyvitamin D. }\end{array}$} \\
\hline${ }^{\mathrm{a}}$ Data are presented a & [IQR] due to $\mathrm{n}$ & al distributio & & \\
\hline
\end{tabular}


Table 2 presented the bivariate correlations with GGT, ALT, and ALP. There was no correlation between $25(\mathrm{OH}) \mathrm{D}$ and any liver enzyme levels (all $p>0.05)$. GGT was positively related to age and $\mathrm{BMI}(\mathrm{p}=0.039$ and 0.041 , respectively). ALP was positively related to diastolic blood pressure $(p<0.05)$ and there was also a positive relationship between GGT and diastolic blood pressure $(p=0.045)$. The three liver enzymes were positively related to each other and to FBG (all $p<0.05)$. However, there were no correlations between any liver enzyme levels and BuN, the same with UA (all $p>0.05$ ). There was no relationship between the three enzymes and the lipid profile (all $p>0.05$ ). 
Table 2

Correlations of 25(OH)D, anthropometric, metabolic and inflammatory markers withGGT, ALT and ALP.

\begin{tabular}{|c|c|c|c|}
\hline & GGT r (p-value) & ALT r (p-value) & ALP r (p-value) \\
\hline $25(\mathrm{OH}) \mathrm{D}(\mathrm{nmol} / \mathrm{L})$ & $0.036(0.489)$ & $-0.038(0.466)$ & $0.026(0.623)$ \\
\hline Age (year) & $0.042(0.039)$ & $-0.156(0.218)$ & $0.047(0.122)$ \\
\hline BMI $\left(\mathrm{kg} / \mathrm{m}^{2}\right)$ & $0.128(0.041)$ & $-0.057(0.233)$ & $0.031(0.059)$ \\
\hline SBP (mmHg) & $0.063(0.051)$ & $0.103(0.154)$ & $0.164(0.201)$ \\
\hline DBP (mmHg) & $0.131(0.043)$ & $-0.097(0.058)$ & $0.212(0.049)$ \\
\hline GLU (mmol/L) & $0.122(0.031)$ & $0.631(0.007)$ & $0.245(0.010)$ \\
\hline BUN (mmol/L) & $0.283(0.242)$ & $0.156(0.214)$ & $0.334(0.257)$ \\
\hline Creatinine (umol/L) & $0.327(0.839)$ & $0.324(0.127)$ & $0.442(0.041)$ \\
\hline UA (umol/L) & $0.083(0.443)$ & $0.051(0.147)$ & $0.304(0.759)$ \\
\hline AST (U/L) & $0.029(0.334)$ & $0.024(0.165)$ & $0.543(0.148)$ \\
\hline HbA1C (\%) & $0.423(0.047)$ & $0.068(0.205)$ & $0.121(0.032)$ \\
\hline HDL (mmol/L) & $0.214(0.326)$ & $0.540(0.005)$ & $0.129(0.504)$ \\
\hline LDL (mmol/L) & $0.229(0.235)$ & $0.115(0.608)$ & $-0.045(0.123)$ \\
\hline Triglyceride (mmol/L) & $0.255(0.011)$ & $0.129(0.094)$ & $0.216(0.026)$ \\
\hline $\mathrm{TP}(\mathrm{g} / \mathrm{L})$ & $0.034(0.059)$ & $0.128(0.031)$ & $0.112(0.066)$ \\
\hline Alb (g/L) & $0.133(0.061)$ & $0.072(0.147)$ & $0.056(0.043)$ \\
\hline WBC $\left(10^{9} / L\right)$ & $0.058(0.129)$ & $0.320(0.071)$ & $0.132(0.095)$ \\
\hline GGT (U/L) & & $0.322(<0.001)$ & $0.320(<0.001)$ \\
\hline ALT (U/L) & $0.322(<0.001)$ & & $0.166(0.001)$ \\
\hline $\operatorname{ALP}(\mathrm{U} / \mathrm{L})$ & $0.320(<0.001)$ & $0.166(0.001)$ & \\
\hline \multicolumn{4}{|c|}{$\begin{array}{l}\text { ALT: alanine aminotransferase; ALP: alkaline phosphatase; BMI: body mass index; SBP: Systolic } \\
\text { blood pressure; DBP: Diastolic blood pressure; GGT: y-glutamyl transferase; HDL: high-density } \\
\text { lipoprotein; LDL: low-density lipoprotein; 25(OH)D: 25-hydroxyvitamin D. }\end{array}$} \\
\hline
\end{tabular}

Lipid profile and AST were not associated with any liver enzymes (all $p>0.05$ ). GGT and ALP were positively associated with $\mathrm{Ghb}(\mathrm{p}=0.047$ and 0.032 respectively). ALT was associated with $\mathrm{HDL}(\mathrm{p}=$ 0.047). GGT and ALP were positively related to triglycerides $(p<0.05)$. However, three liver enzymes had no correlations with the levels of ALB and WBC (all $p>0.05$ ). 
In multiple linear regression analysis, GGT, ALT or ALP levels remained unrelated to 25(OH)D concentration after adjustments for covariates including age, BMI, sex, BuN, Cr, UA,AST, Ghb, cholesterol, $\mathrm{HDL}, \mathrm{LDL}$, and total protein, ALB and WBC (Table 3a-3c) (all $p>0.1)$. In these models, GGT was associated with sex $(p<0.01)$ (Table 3a). ALT was related to sex and BuN (all $p<0.05)($ Table $3 b)$. ALP was associated with AST and triglycerides (all $p<0.05$ ). When categorized based on $25(\mathrm{OH}) \mathrm{D}$ concentration, 203 participants had 25(OH)D $<25$ nmol/L, 159 participants had 25(OH)D of 25$50 \mathrm{nmol} / \mathrm{L}$, and 6 participants had 25(OH)D $>50 \mathrm{nmol} / \mathrm{L}$. There were no significant differences in GGT, ALT or ALP according to vitamin D categories (Kruskal-Wallis test, all $p>0.05$ ). 
Table 3

a.Multiple linear regression analyses for GGT.

\begin{tabular}{|c|c|c|c|c|c|}
\hline \multirow[t]{2}{*}{ Dependent variable } & \multirow[t]{2}{*}{ Independent variable } & \multicolumn{2}{|c|}{ Model 1} & \multicolumn{2}{|c|}{ Model 2} \\
\hline & & $\beta$ & p-value & $\beta$ & p-value \\
\hline \multirow[t]{19}{*}{ GGT } & $25(\mathrm{OH}) \mathrm{D}$ & 0.23 & 0.12 & 0.07 & 0.45 \\
\hline & Age & -0.02 & 0.57 & 0.31 & 0.15 \\
\hline & BMI & 0.03 & 0.45 & 0.18 & 0.06 \\
\hline & Sex & 0.39 & $<0.01$ & 0.27 & 0.44 \\
\hline & SBP & & & & \\
\hline & DBP & & & & \\
\hline & GLU & & & 0.07 & 0.06 \\
\hline & BUN & 0.16 & 0.25 & 0.29 & 0.37 \\
\hline & Creatinine & -0.07 & 0.44 & 0.31 & 0.45 \\
\hline & UA & 0.31 & 0.15 & 0.18 & 0.19 \\
\hline & AST & 0.19 & 0.07 & 0.27 & 0.56 \\
\hline & HbA1C & 0.04 & 0.05 & 0.25 & 0.20 \\
\hline & HDL & 0.28 & 0.27 & 0.13 & 0.55 \\
\hline & LDL & 0.37 & 0.42 & 0.24 & 0.05 \\
\hline & Triglyceride & 0.15 & 0.29 & & \\
\hline & TP & 0.07 & 0.53 & 0.22 & 0.38 \\
\hline & Alb & 0.24 & 0.10 & 0.21 & 0.41 \\
\hline & WBC & 0.11 & 0.61 & 0.39 & 0.57 \\
\hline & $\mathrm{R}^{2}$ (p-value) & 0.46 & $<0.01$ & 0.45 & $<0.01$ \\
\hline
\end{tabular}

Model 1: adjusted for age, sex, BMI, SBP, DBP, BUN, Creatinine, UA, AST, HbA1C, HDL, LDL, Triglyceride, TP, Alb, WBC.

Model 2 adjusted for age, sex, BMI, SBP, DBP, GLU, BUN, Creatinine, UA, AST, HbA1C, HDL, LDL, TP, Alb, WBC. 
Table 3

b.Multiple linear regression analyses for ALT.

\begin{tabular}{|c|c|c|c|c|c|}
\hline \multirow[t]{2}{*}{ Dependent variable } & \multirow[t]{2}{*}{ Independent variable } & \multicolumn{2}{|c|}{ Model 1} & \multicolumn{2}{|c|}{ Model 2} \\
\hline & & $\beta$ & p-value & $\beta$ & p-value \\
\hline \multirow[t]{19}{*}{ ALT } & $25(\mathrm{OH}) \mathrm{D}$ & 0.14 & 0.26 & 0.08 & 0.34 \\
\hline & Age & 0.05 & 0.39 & 0.22 & 0.17 \\
\hline & BMI & 0.16 & 0.41 & 0.35 & 0.19 \\
\hline & Sex & 0.34 & 0.02 & -0.07 & 0.31 \\
\hline & SBP & 0.07 & 0.23 & 0.14 & 0.07 \\
\hline & DBP & -0.14 & 0.12 & -0.12 & 0.26 \\
\hline & GLU & & & 0.18 & 0.05 \\
\hline & BUN & 0.17 & 0.02 & 0.13 & 0.30 \\
\hline & Creatinine & 0.29 & 0.38 & 0.26 & 0.14 \\
\hline & UA & 0.28 & 0.43 & -0.02 & 0.29 \\
\hline & AST & 0.17 & 0.06 & 0.03 & 0.57 \\
\hline & $\mathrm{HbA1C}$ & 0.09 & 0.45 & 0.38 & 0.11 \\
\hline & $\mathrm{HDL}$ & 0.31 & 0.15 & & \\
\hline & LDL & 0.18 & 0.06 & 0.27 & 0.18 \\
\hline & Triglyceride & 0.27 & 0.34 & 0.24 & 0.03 \\
\hline & TP & -0.02 & 0.13 & 0.39 & 0.21 \\
\hline & Alb & 0.42 & 0.15 & 0.46 & 0.35 \\
\hline & WBC & 0.33 & 0.27 & 0.48 & 0.23 \\
\hline & $R^{2}$ (p-value) & 0.31 & $<0.01$ & 0.16 & $<0.01$ \\
\hline
\end{tabular}

Model 1: adjusted for age, sex, BMI, SBP, DBP, BUN, Creatinine, UA, AST, HbA1C, HDL, LDL, Triglyceride, TP, Alb, WBC.

Model 2 Model 1: adjusted for age, sex, BMI, SBP, DBP, GLU, BUN, Creatinine, UA, AST, HbA1C, LDL, Triglyceride, TP, Alb, WBC. 
Table 3

b.Multiple linear regression analyses for ALT.

\begin{tabular}{|c|c|c|c|c|c|}
\hline \multirow[t]{2}{*}{ Dependent variable } & \multirow[t]{2}{*}{ Independent variable } & \multicolumn{2}{|c|}{ Model 1} & \multicolumn{2}{|c|}{ Model 2} \\
\hline & & $\beta$ & p-value & $\beta$ & p-value \\
\hline \multirow[t]{19}{*}{ ALT } & $25(\mathrm{OH}) \mathrm{D}$ & 0.14 & 0.26 & 0.08 & 0.34 \\
\hline & Age & 0.05 & 0.39 & 0.22 & 0.17 \\
\hline & BMI & 0.16 & 0.41 & 0.35 & 0.19 \\
\hline & Sex & 0.34 & 0.02 & -0.07 & 0.31 \\
\hline & SBP & 0.07 & 0.23 & 0.14 & 0.07 \\
\hline & DBP & -0.14 & 0.12 & -0.12 & 0.26 \\
\hline & GLU & & & 0.18 & 0.05 \\
\hline & BUN & 0.17 & 0.02 & 0.13 & 0.30 \\
\hline & Creatinine & 0.29 & 0.38 & 0.26 & 0.14 \\
\hline & UA & 0.28 & 0.43 & -0.02 & 0.29 \\
\hline & AST & 0.17 & 0.06 & 0.03 & 0.57 \\
\hline & $\mathrm{HbA1C}$ & 0.09 & 0.45 & 0.38 & 0.11 \\
\hline & $\mathrm{HDL}$ & 0.31 & 0.15 & & \\
\hline & LDL & 0.18 & 0.06 & 0.27 & 0.18 \\
\hline & Triglyceride & 0.27 & 0.34 & 0.24 & 0.03 \\
\hline & $\mathrm{TP}$ & -0.02 & 0.13 & 0.39 & 0.21 \\
\hline & Alb & 0.42 & 0.15 & 0.46 & 0.35 \\
\hline & WBC & 0.33 & 0.27 & 0.48 & 0.23 \\
\hline & $R^{2}$ (p-value) & 0.31 & $<0.01$ & 0.16 & $<0.01$ \\
\hline
\end{tabular}

Model 1: adjusted for age, sex, BMI, SBP, DBP, BUN, Creatinine, UA, AST, HbA1C, HDL, LDL, Triglyceride, TP, Alb, WBC.

Model 2 Model 1: adjusted for age, sex, BMI, SBP, DBP, GLU, BUN, Creatinine, UA, AST, HbA1C, LDL, Triglyceride, TP, Alb, WBC.

\section{Discussion}

The cross-sectional study was conducted to examine the association between 25(OH)D concentration and liver enzymes, showing no association with healthy adults, before and after adjustment for potential 
confounding factors, including age, sex, markers of adiposity, insulin sensitivity, lipids and inflammation. Liver enzymes were related to the metabolic syndrome (MS) factors including FBG and triglycerides. Additionally, GGT, ALT and ALP were positively interacted to each other. Similarly, Ballestri et al. demonstrated that liver histology changes could be predicted significantly using ALT, AST, homeostasis model of assessment-insulin resistance (HOMA-IR), serum uric acid (SUA), MS, total cholesterol (TCH) and serum iron[10].

Vitamin $D$ can be acquired from the diet, but it is mainly produced by endogenous sun exposure[11]. Transported to the liver, vitamin $\mathrm{D}$ is hydroxylated to $25(\mathrm{OH}) \mathrm{D}$ by monooxygenase system in microsome. It is generally accepted that serum $25(\mathrm{OH}) \mathrm{D}$ concentration could be used to assess status of vitamin $\mathrm{D}$ and musculoskeletal growth. What's more, nutritional guidelines of vitamin $D$ should be based on effects of vitamin D[12]. It is well known that vitamin D is beneficial to calcium and bone metabolism. Studies have confirmed that vitamin $D$ has a series of physiological functions and its deficiency can lead to many diseases. Recent studies have shown that it regulates adaptive immune responses to various inflammatory and autoimmune diseases. Both vitamin D hydroxylase and vitamin D receptor (VDR) were expressed in immune cells, which lay a foundation for vitamin $D$ to play its role in inflammatory diseases. $25(\mathrm{OH}) \mathrm{D}$ acts as a ligand for the VDR and participates in diverse physiological processes[13]. Furthermore, increased ALT, GGT and ALP, which were closely associated with liver fat deposition, were considered as indices of liver injury[14-17]. As mentioned earlier, ALT can serve as an index of hepatocyte death and an indirect maker of liver injury $[15,18]$. GGT involving in the extracellular catabolism of the antioxidant glutathione was regarded as a marker of oxidative stress and sub-clinical inflammation[16]. ALP was responsible for hydrolysis of phosphate esters. An up to triple improvement of ALP was common to see in hepatocellular diseases, accompanied with elevated aminotransferases[19]. At the same time, ALP was significantly increased in cholestatic hepatobiliary diseases as well, for instance, primary biliary intrahepatic cholestasis[13]. However, the real fact was that AST was a less specific index of liver injury on account of wide secretion from other organs and cells, such as the heart, skeletal muscle, kidney, pancreas, lung, leukocyte, and erythrocyte[18-20].

Similar to our findings, three articles were presented to support our conclusion. The first one from the third National Health and Nutrition Examination Survey (NHANES III) showed no correlation between $25(\mathrm{OH}) \mathrm{D}$ concentration and serum ALT levels. The result of this study was consistent with previous irrelevance outcome between ALT and 25(OH)D concentration[15]. However, the study showed that the lower quartile of 25(OH)D had a higher prevalence of unexplained ALT, individuals with elevated ALT levels $(n=308)$ had a lower concentration of $25(\mathrm{OH})$ D, compared to BMI-matched controls $(n=976)$. Notably, individuals with different comorbidities such as diabetes and hypertension were included, and drug use was not adjusted, which may have affected their results. The second study consisted of 654 individuals with risk factors for diabetes(aged $\geq 30$ years) reported an inverse association of $25(\mathrm{OH}) \mathrm{D}$ concentration and ALT, after adjusting for BMl, waist circumference, and lipids[16]. In contrast, the third study using NHANES III data for 12,155 participants with normal ALT levels, demonstrated a positive association between 25(OH)D concentration and ALT levels, after adjusting for confounding factors, such as gender, race, BMI, diabetes, high blood pressure, smoking and drinking history. One thing to be noted 
was that all individuals with serum ALT levels > $39 \mathrm{U} / \mathrm{L}$ were excluded in their study. However, our study did not require ALT levels and everyone included. Therefore, their findings were not comparable to other conclusions, as higher ALT levels may be related to liver damage and severe comorbidities.

There were some limitations in our study. Firstly, due to the cross-sectional design of our study, we can't conclude cause and effect relationships and evaluate the impact of vitamin D status over time. Secondly, vitamin $D$ concentration is measured for one time. However, a previous study declared that a single measurement of serum 25(OH)D had reasonable validity over a 5-year period[21]. Multiple measurements of 25(OH)D would estimate the vitamin D status better and reduce the extent of non-differential measurement errors. Thirdly, the status of vitamin D may be confusing because vitamin D concentrations may generally be influenced by a different lifestyles[22, 23]. In our model, we have adjusted other determinants. However, possible residual confusion may not be ruled out. Finally, adverse effects of vitamin D use were not discussed in this article. More deep research for liver injury should be carried out to re-evaluate and determine relationships between 25-hydroxyvitamin D concentration and liver enzymes, using larger sample sizes, longer durations and more sensitive screening tools.

\section{Conclusion}

In conclusion, evidence from some but not all cross-sectional studies suggested a relationship between 25(OH)D concentration and liver enzymes, which were within the normal ranges. The reason why our results were not related to the $25(\mathrm{OH}) \mathrm{D}$ concentration and ALT levels were that our sample size was large and the participants were older (our sample median age $=49$ ). In our study performed in Chinese population within 368 healthy drug-naïve individuals, the results showed there was no association between $25(\mathrm{OH})$ D concentration and GGT, ALT or ALP levels.

\section{Abbreviations}

ALP

alkaline phosphatase; ALT:alanine aminotransferase; BMI:Body mass index;

FBG

fasting blood-glucose; Ghb:glycated hemoglobin; GGT:glutamyl transferase; NAFLD non-alcoholic fatty liver disease; NHANES III:the third National Health and Nutrition Examination Survey; WBC:white blood cell

\section{Declarations}

\section{Acknowledgments}

We thank all the people who were involved in this study. This project was supported by the National Natural Science Foundation of China (Nos.81700522, 81470003), the Provincial Natural Science 
Research Project of Colleges and Universities of Anhui Province (No. KJ2016A348), the fund of Anhui medical university doctoral start research (No.0601067101), 2017 public welfare technology application research linkage project of Anhui province (No.1704f0804019) and Humanities and Social Science Research Project of Colleges and Universities of Anhui Province (No. SK2016A0482), Natural Science Foundation of Anhui Province (1808085MH235).

\section{Authors' contributions}

TX and FP designed the study. JW, LL and HH participated in the collecting and analyzing of the data. QY and PL finished the manuscript. YL revised and edited the manuscript. SC reviewed the manuscript. All authors approved the final version of the manuscript for publication.

\section{Funding}

The National Natural Science Foundation of China (Nos. 81700522, 81470003), from the National Natural Science Foundation of China, supports the design of the study.

The Provincial Natural Science Research Project of Colleges and Universities of Anhui Province (No. KJ2016A348), from the Education Department of Anhui, China, supports the collection of data.

The fund of Anhui medical university doctoral start research (No.0601067101), from the Anhui Medical University, China, supports the analysis of data.

2017 public welfare technology application research linkage project of Anhui province (No.1704f0804019), from Anhui Province Science and Technology Department, China, supports the analysis of data.

Humanities and Social Science Research Project of Colleges and Universities of Anhui Province (No. SK2016A0482), from Anhui Province Science and Technology Department, China, supports the interpretation of data.

Natural Science Foundation of Anhui Province(1808085MH235), from the Education Department of Anhui, China, supports the writing of manuscript.

\section{Availability of data and materials}

The datasets analyzed during the current study are available from the corresponding author on reasonable request.

\section{Ethics approval and consent to participate}

The ethical approval was obtained from the Ethical Committee of Anhui Medical University (Protocol ID: 20170248). All patients and healthy persons included in this study provided written informed consent. 
The clinical trial information sheath was given to all patients that include the objectives, methodology and purpose of the study using a simple layman terms.

\section{Consent for publication}

Not applicable.

\section{Competing interests}

The authors declare that they have no competing interests.

\section{References}

1. Barchetta I, Angelico F, Del Ben M, Baroni MG, Pozzilli P, Morini S, Cavallo MG. Strong association between non alcoholic fatty liver disease (NAFLD) and low 25(OH) vitamin D levels in an adult population with normal serum liver enzymes. BMC Med. 2011;9:85.

2. Jeon SM, Shin EA. Exploring vitamin D metabolism and function in cancer. Exp Mol Med. 2018;50(4):20.

3. Gu J, Wang C, Zhang H, Yue H, Hu W, He J, Fu W, Zhang Z. No association between the vitamin D pathway gene polymorphisms and bone biomarkers response to calcium and low dose calcitriol supplementation in postmenopausal Chinese women: a one-year prospective study. Biomarkers. 2018;23(7):664-9.

4. Farnik H, Bojunga J, Berger A, Allwinn R, Waidmann O, Kronenberger B, Keppler OT, Zeuzem S, Sarrazin C, Lange CM. Low vitamin D serum concentration is associated with high levels of hepatitis B virus replication in chronically infected patients. Hepatology. 2013;58(4):1270-6.

5. Yildiz I, Erol OB, Toprak S, Cantez MS, Omer B, Kilic A, Oguz F, Uysalol M, Yekeler E, Unuvar E. Role of vitamin D in children with hepatosteatosis. J Pediatr Gastroenterol Nutr. 2014;59(1):106-11.

6. Eliades M, Spyrou E, Agrawal N, Lazo M, Brancati FL, Potter JJ, Koteish AA, Clark JM, Guallar E, Hernaez R. Meta-analysis: vitamin D and non-alcoholic fatty liver disease. Aliment Pharmacol Ther. 2013;38(3):246-54.

7. Cicero AFG, Colletti A, Bellentani S. Nutraceutical Approach to Non-Alcoholic Fatty Liver Disease (NAFLD): The Available Clinical Evidence. Nutrients 2018, 10(9).

8. Naderpoor N, Mousa A, de Courten M, Scragg R, de Courten B. The relationship between 25hydroxyvitamin $\mathrm{D}$ concentration and liver enzymes in overweight or obese adults: Cross-sectional and interventional outcomes. J Steroid Biochem Mol Biol. 2018;177:193-9.

9. Wang X, Li W, Zhang Y, Yang Y, Qin G: Association between vitamin D and non-alcoholic fatty liver disease/non-alcoholic steatohepatitis: results from a meta-analysis. International journal of clinical and experimental medicine 2015, 8(10):17221-17234.

10. Ballestri S, Nascimbeni F, Romagnoli D, Lonardo A. The independent predictors of non-alcoholic steatohepatitis and its individual histological features.: Insulin resistance, serum uric acid, metabolic 
syndrome, alanine aminotransferase and serum total cholesterol are a clue to pathogenesis and candidate targets for treatment. Hepatol Res. 2016;46(11):1074-87.

11. Jenab M, Bueno-de-Mesquita HB, Ferrari P, van Duijnhoven FJ, Norat T, Pischon T, Jansen EH, Slimani $\mathrm{N}$, Byrnes $\mathrm{G}$, Rinaldi $\mathrm{S}$, et al. Association between pre-diagnostic circulating vitamin $\mathrm{D}$ concentration and risk of colorectal cancer in European populations:a nested case-control study. BMJ. 2010;340:b5500.

12. Pilz S, Trummer C, Pandis M, Schwetz V, Aberer F, Grubler M, Verheyen N, Tomaschitz A, Marz W. Vitamin D: Current Guidelines and Future Outlook. Anticancer Res. 2018;38(2):1145-51.

13. Ishizawa M, Akagi D, Yamamoto J, Makishima M. 1alpha,25-Dihydroxyvitamin D3 enhances TRPV6 transcription through p38 MAPK activation and GADD45 expression. J Steroid Biochem Mol Biol. 2017;172:55-61.

14. Choi KM, Han K, Park S, Chung HS, Kim NH, Yoo HJ, Seo JA, Kim SG, Kim NH, Baik SH, et al. Implication of liver enzymes on incident cardiovascular diseases and mortality: A nationwide population-based cohort study. Sci Rep. 2018;8(1):3764.

15. Agrawal S, Dhiman RK, Limdi JK. Evaluation of abnormal liver function tests. Postgrad Med J. 2016;92(1086):223-34.

16. Kunutsor SK. Gamma-glutamyltransferase-friend or foe within? Liver Int. 2016;36(12):1723-34.

17. Liu CF, Zhou WN, Lu Z, Wang XT, Qiu ZH. The associations between liver enzymes and the risk of metabolic syndrome in the elderly. Exp Gerontol. 2018;106:132-6.

18. Green RM, Flamm S. AGA technical review on the evaluation of liver chemistry tests. Gastroenterology. 2002;123(4):1367-84.

19. Woreta TA, Alqahtani SA. Evaluation of abnormal liver tests. Med Clin North Am. 2014;98(1):1-16.

20. Xu Q, Higgins T, Cembrowski GS. Limiting the testing of AST: a diagnostically nonspecific enzyme. Am J Clin Pathol. 2015;144(3):423-6.

21. El-Ansary A, Cannell JJ, Bjorklund G, Bhat RS, Al Dbass AM, Alfawaz HA, Chirumbolo S, Al-Ayadhi L. In the search for reliable biomarkers for the early diagnosis of autism spectrum disorder: the role of vitamin D. Metab Brain Dis. 2018;33(3):917-31.

22. Lopez-Bautista F, Posadas-Romero C, Ruiz-Vargas LY, Cardoso-Saldana G, Juarez-Rojas JG, MedinaUrrutia A, Perez-Hernandez N, Rodriguez-Perez JM, Vargas-Alarcon G, Posadas-Sanchez R. Vitamin D Deficiency is not Associated with Fatty Liver in a Mexican Population. Ann Hepatol. 2018;17(3):41925.

23. Hofmann JN, Yu K, Horst RL, Hayes RB, Purdue MP. Long-term variation in serum 25-hydroxyvitamin D concentration among participants in the Prostate, Lung, Colorectal, and Ovarian Cancer Screening Trial. Cancer Epidemiol Biomarkers Prev. 2010;19(4):927-31. 